\title{
Forthcoming articles
}

Visit First View via cambridge.org/lin to access articles and book reviews prior to print publication.

\section{Mohammed Nour Abu Guba}

Gemination within English loanwords in Ammani Arabic: An Optimalitytheoretic analysis

\section{Daniel Altshuler \& Laura Michaelis}

By now: Change of state, epistemic modality and evidential inference

(Special issue: Beyond time)

\section{George Bailey}

Insertion and deletion in Northern English (ng): Interacting innovations in the life cycle of phonological processes

Thomas Berg, Tim Zingler \& Arne Lohmann

The range of linguistic units: Distance effects in English mandative subjunctive constructions

Claire Bonial \& Kimberley A. Pollard

Choosing an event description: What a PropBank study reveals about the contrast between light verb constructions and counterpart synthetic verbs (Special issue: Beyond time)

Amanda Cardoso \& Patrick Honeybone

Palatalisation can be quantity-sesitive: Dorsal Fricative Assimilation in Liverpool English

\section{Elena Castroviejo}

On wh-exclamatives and gradability: An argument from Romance

\section{Claire Childs}

The grammaticalisation of never in British English dialects: Quantifying syntactic and functional change

Astrid De Wit, Peter Petré \& Frank Brisard

Standing out with the progressive

(Special issue: Beyond time)

Stephen Dickey

Time out of tense: Russian aspect in the imperative

(Special issue: Beyond time) 
Pablo Fuentes

Future obligations

Schinichiro Fukuda

The syntax of variable behavior verbs: Experimental evidence from the accusative-oblique alternations in Japanese

Peppina Po-Lun Lee

On the semantics of classifier reduplication in Cantonese

John J. Lowe

Mixed projections and syntactic categories

Louise Mycock

The intonation of the Q-marking construction: A comparison of Hungarian and Slovenian

Tim Nisbet

Meaning, metaphor, and argument structure

Jerzy Rubach

Chain effects in Kurpian

Fabian Tomaschek, Ingo Plag, Mirjam Ernestus \& R. Harald Baayen

Phonetic effects of morphology and context: Modeling the duration of word-final S in English with Naïve Discriminative Learning

Susagna Tubau

The asymmetric behavior of English negative quantifiers in negative sentences

Danielle Turton \& Maciej Baranowski

Not quite the same: The social and phonetic conditioning of the FOOTSTRUT vowels in Manchester

Hiroto Uchihara \& Gregorio Tiburcio Cano

A phonological account of Tlapanec (Mè'phàà) tonal alternations

Jim Wood, Matthew Barros \& Einar Freyr Sigurðsson

Case mismatching in Icelandic clausal ellipsis 